\title{
First principle investigation of the exposed surfaces and morphology of $\beta-\mathrm{ZnMoO}_{4}$
}

Cite as: J. Appl. Phys. 126, 235301 (2019); https://doi.org/10.1063/1.5131260

Submitted: 11 October 2019. Accepted: 02 December 2019 . Published Online: 17 December 2019

Renan A. P. Ribeiro (D), Marisa C. Oliveira (D), Alexsandro Gama de Sousa, Maurício R. D. Bomio (iD, Fabiana V. Motta (D), Lourdes Gracia (D), Sergio R. de Lazaro (D), Elson Longo (iD), and Juan Andrés

\section{COLLECTIONS}

Paper published as part of the special topic on Defects in Semiconductors 2020

Note: This paper is part of the Special Topic on Defects in Semiconductors 2020.
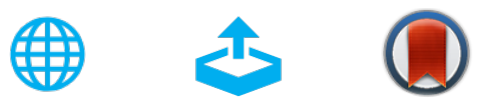

\section{ARTICLES YOU MAY BE INTERESTED IN}

Magnetic exchange interactions and band gap bowing in $\mathrm{Ni}_{x} \mathrm{Mg} \mathrm{g}_{-\mathrm{x}} \mathrm{O}(0.0 \leq \mathrm{x} \leq 1.0)$ : $\mathrm{A} G \mathrm{GA}+\mathrm{U}$ density functional study

Journal of Applied Physics 126, 233904 (2019); https://doi.org/10.1063/1.5126744

Atomic-scale quantitative analysis of implanted Mg in annealed GaN layers on free-standing GaN substrates

Journal of Applied Physics 126, 235704 (2019); https://doi.org/10.1063/1.5132345

Advanced material system for the design of an intermediate band solar cell: Type-II CdTe quantum dots in a ZnCdSe matrix

Journal of Applied Physics 126, 235302 (2019); https://doi.org/10.1063/1.5126224

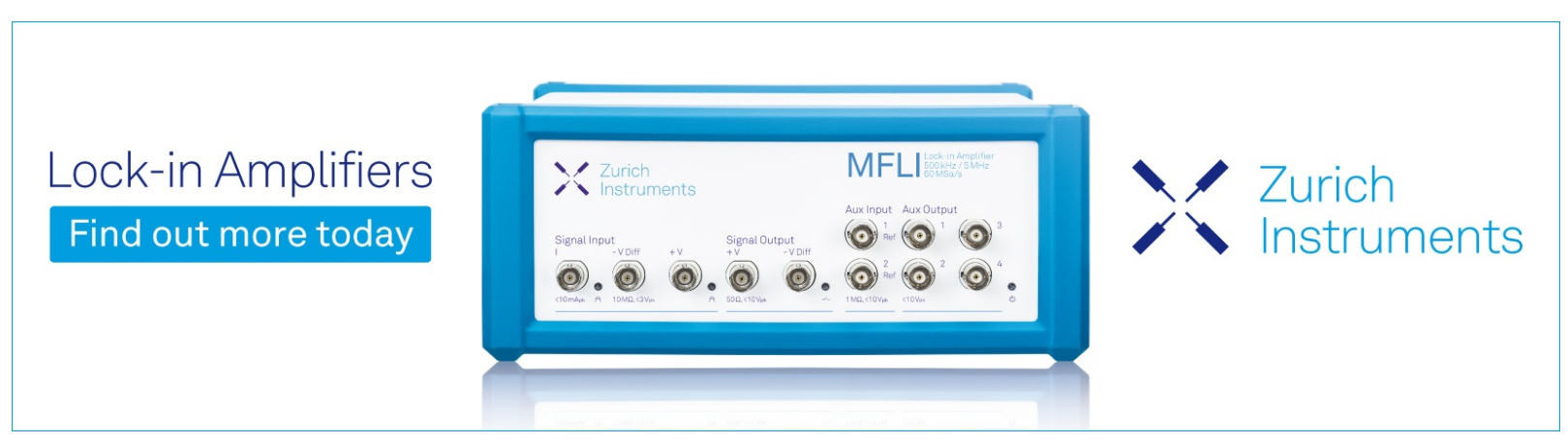




\title{
First principle investigation of the exposed surfaces and morphology of $\beta-\mathrm{ZnMoO}_{4}$
}

\author{
Cite as: J. Appl. Phys. 126, 235301 (2019); doi: 10.1063/1.5131260 \\ Submitted: 11 October 2019 . Accepted: 2 December 2019 . \\ Published Online: 17 December 2019
}

Renan A. P. Ribeiro, ${ }^{1, a)}$ (1D Marisa C. Oliveira, ${ }^{2}$ (D) Alexsandro Gama de Sousa, ${ }^{3}$ Maurício R. D. Bomio, ${ }^{2}$ (iD Fabiana V. Motta, ${ }^{2}$ (D) Lourdes Gracia, ${ }^{4, b)}$ (D) Sergio R. de Lazaro, ${ }^{5}$ (D) Elson Longo, (D) and Juan Andrés ${ }^{3}$

\begin{abstract}
AFFILIATIONS
${ }^{1}$ CDMF-UFSCar, Universidade Federal de São Carlos, PO Box 676, 13565-905 São Carlos, São Paulo, Brazil

${ }^{2}$ LSQM-Laboratório de Síntese Química de Materiais, DEMat, Universidade Federal do Rio Grande do Norte-U UFRN, P.O. Box 1524, 59078-970 Natal, Rio Grande do Norte, Brazil

${ }^{3}$ Department of Exact and Natural Sciences, Universidade Estadual do Sudoeste da Bahia, Campus de Itapetinga, BR 415, KM 03, S/No, 45700-000 Itapetinga, Bahia, Brazil

${ }^{4}$ Departament de Química Física i Analítica, Universitat Jaume I, 12071 Castelló de la Plana, Spain

${ }^{5}$ Department of Chemistry, State University of Ponta Grossa, Av. Gen. Carlos Cavalcanti, n 4748, 84030-900 Ponta Grossa,

Paraná, Brazil
\end{abstract}

Note: This paper is part of the Special Topic on Defects in Semiconductors 2020.

${ }^{a}$ Author to whom correspondence should be addressed: ribeiroapr@gmail.com

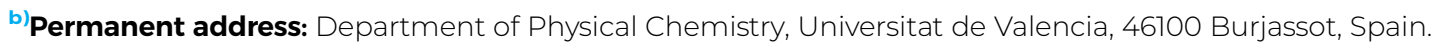

\begin{abstract}
Crystal shape is a critical determinant of the physical and chemical properties of crystalline materials; hence, it is the challenge of controlling the crystal morphology in a wide range of scientific and technological applications. The morphology is related to the geometry of their exposed surfaces, which can be described by their surface energies. The surface properties of $\beta-\mathrm{ZnMoO}_{4}$ have not yet been well explored, either experimentally or theoretically. Thus, the first-principle calculation at the density functional theory level was carried out for different low-index surfaces of $\beta-\mathrm{ZnMoO}_{4}$, specifically (001), (010), (110), (011), (101), and (111), and the surface energy values ( $\left.\mathrm{E}_{\text {surf }}\right)$ were reported. The surface stability was found to be controlled by the undercoordinated $\left[\mathrm{MoO}_{\mathrm{n}} \ldots y V_{O}^{x}\right]$ and $\left[\mathrm{ZnO}_{\mathrm{n}} \ldots y V_{O}^{x}\right](\mathrm{n}=4$ and $5 ; \mathrm{y}=1$ and 2$)$ clusters, i.e., their local coordination of $\mathrm{Mo}$ and $\mathrm{Zn}$ cations at the exposed surfaces, respectively, with the (111) surface being the most stable. A complete map of investigated $\beta-\mathrm{ZnMoO}_{4}$ morphologies was obtained using the Wulff construction and changing the values of the calculated energy surfaces. The final geometries from this map were compared with field emission-scanning electron microscopy images showing excellent agreement, prevising rectangular and hexagonal plates. Our findings will promote the use of facet engineering and might provide strategies to produce $\beta-\mathrm{ZnMoO}_{4}$-based materials for achieving morphology-dependent technological applications.
\end{abstract}

Published under license by AIP Publishing. https://doi.org/10.1063/1.5131260

\section{INTRODUCTION}

The facets of each surface are the key parameters that should be rationally selected to control the morphology, since they directly impact the physical and chemical properties of crystals and become a way of tuning their applications in catalysis, sensors, and energy conversion, among others. ${ }^{1-6}$ Investigating facets is an interdisciplinary research field in which significant efforts have been devoted in recent years to understand the growth and processing of advanced crystalline materials to successfully realize their functional applications. $^{7-14}$ Studying surface properties and morphologydependent properties can help to better control and achieve the functionality of specific material surfaces. To this end, it is mandatory to study their exposed surfaces and to know how the atoms located on the exposed surfaces of a crystal are coordinated to their nearest neighbors and, thus, the landscape of the surface electronic structure. $8,15,16$ 
In general, the properties and functions of any crystal are highly dependent on its surface composition, geometry, morphology and electronic structures, and the morphology results from the relative stability of the exposed surfaces. The equilibrium morphology of a crystal and its evolution can be predicted by the classical Wulff construction, and its generalizations have been well-recognized procedures for a long time ${ }^{17-22}$ to obtain the morphology of materials ${ }^{3-19}$ and require surface energies to be known. ${ }^{23,24}$

It is important to remark that, despite its importance, experimentally measuring or calculating surface energies of a crystal is generally a difficult task even for simple cases, because the exposed surfaces are in very diverse environments, and different parameters such as temperature, $\mathrm{pH}$, surfactants, or other adsorbates on the crystal surface can modify the surface energy. ${ }^{25-29}$ First-principle calculations are well-suited to obtain the values of the surface energies for different exposed surfaces. ${ }^{30}$ As a result, the atomic and electronic properties of a crystal surface can be revealed and can provide a fundamental understanding of the influence of synthesis factors on the material morphology. ${ }^{31-33}$ The predicted crystal morphology explores the chemical entities of the material emerging from different exposed surfaces of the crystal, which help to find a relationship between the crystal morphology and the atom arrangement in the crystal lattice, opening the future of shape selective design to technological applications. ${ }^{34-38}$

Experimental characterizations of surface structures and morphology can be achieved due to the recent advancement in microscopy, namely, field emission-scanning electron microscopy (FE-SEM), and provide a viable route for directly characterizing crystals upon variable experimental conditions. ${ }^{39-45}$ Better understanding and control of the exposed surfaces would bring innovative capabilities to design adequate structures with enhanced applications. Therefore, modulating crystallographic surfaces of functional materials into desirable morphologies has long been actively considered. ${ }^{6,46-52}$ Nevertheless, theoretical frameworks providing fresh insight into the structure and stability of surfaces are vital steps toward realizing the true potential of complex materials and thin films. Our group is engaged in a research project in which the joint use of theoretical and experimental investigation has been performed on the geometry, electronic structure, and optical properties of different members of the metal molybdate family, implementing a wide range of scientifically and technologically noteworthy applications. ${ }^{30,53-63}$ In particular, zinc molybdate $\left(\mathrm{ZnMoO}_{4}\right)$ is a representative member of these widely investigated inorganic materials due to its attractive features. ${ }^{55,64-71}$

The multifunctional properties of $\mathrm{ZnMoO}_{4}$ complex ternary oxides are influenced by the surface structure. Therefore, their surface controlled synthesis is not only a rational route to study the relationship between the morphology and the surface structuredependent properties but also a feasible approach for developing highly active materials such as catalysts and sensors. However, the importance of exposed surfaces, morphology, and their evolution has not been systematically taken into account to the best of our knowledge. Herein, first-principle calculations are carried out to explore the morphology of $\beta-\mathrm{ZnMoO}_{4}$ surface properties, such as atomic configurations and stabilities, broken surface bonds, their cleavage nature, and the degree of surface relaxation for six lowindex (001), (010), (110), (011), (101), and (111) surfaces. We have provided a further detailed analysis of the relationship between the surface structures and their stabilities. Finally, the equilibrium shape and a complete map of available morphologies of the $\beta-\mathrm{ZnMoO}_{4}$ crystal were drawn using the Wulff construction. Our findings provide useful insights into the basic understanding of the anisotropic surface properties of $\beta-\mathrm{ZnMoO}_{4}$ and represent an important step toward rationalizing their morphology control.

\section{COMPUTATIONAL DETAILS}

First-principle calculations were conducted within the framework of the density functional theory (DFT) using the CRYSTAL14 ${ }^{72}$ software package with the B3LYP hybrid function. ${ }^{73,74}$ Here, it is important to point out that Becke-based hybrid exchange correlation functional was selected due to the good agreement between the calculated and experimental bandgaps of complex oxide materials. ${ }^{75-79}$ Diagonalization of the Fock matrix was performed at adequate k-point grids in the reciprocal space. ${ }^{80}$ The thresholds controlling the accuracy of the Coulomb and exchange integral calculations were set to $10^{-8}$ (ITOL1 to ITOL4) and $10^{-14}$ (ITOL5), respectively. The converge criterion for mono- and bielectronic integrals was set to $10^{-8} \mathrm{Ha}$, while the root-mean-square (RMS) gradient, RMS displacement, maximum gradient, and maximum displacement were set to $3 \times 10^{-4}, 1.2 \times 10^{-3}, 4.5 \times 10^{-4}$, and $1.8 \times 10^{-3}$ a.u., respectively.

The monoclinic crystalline structure of bulk $\beta-\mathrm{ZnMoO}_{4}$, as depicted in Fig. 1, was built based on experimental results (Rietveld refinement) ${ }^{70}$ and fully relaxed (lattice parameters and atomic positions). The $\mathrm{Zn}, \mathrm{Mo}$, and $\mathrm{O}$ atoms were described by HAYWSC-311(d31)G, 86-411d31G, and 6-31G* Gaussian basis set, respectively. ${ }^{81-83}$

Different surfaces were modeled in the second step by using unreconstructed (truncated bulk) slab models with calculated equilibrium geometries. The (001), (010), (110), (011), (101), and (111) surfaces of $\beta-\mathrm{ZnMoO}_{4}$ were simulated considering symmetrical slabs (with respect to the mirror plane). All surfaces were terminated with $\mathrm{O}$ planes, and the resulting slab models after the corresponding optimization process and thickness convergence tests consisted of four molecular units containing 24 atoms, as shown in Fig. 1.

The $\mathrm{E}_{\text {surf }}$ was calculated by using the following equation: ${ }^{32}$

$$
\mathrm{E}_{\text {surf }}=\frac{\left(\mathrm{E}_{\text {slab }}-n \mathrm{E}_{\text {bulk }}\right)}{2 A} .
$$

In this case, $\mathrm{n}$ is the number of surface molecular units, $\mathrm{E}_{\mathrm{bulk}}$ is the total energy of the bulk, $E_{\text {slab }}$ is the total energy of the surface slab per molecular unit, and $A$ is the surface area. The equilibrium shape of a crystal can be calculated by utilizing Wulff constructions that minimize the total surface free energy at a fixed volume, providing a simple relationship between the $\mathrm{E}_{\text {surf }}$ of a (hkl) plane and its distance from the crystallite center in the normal direction. ${ }^{84}$ The Visualization for Electronic and Structural Analysis (VESTA) program was used to obtain morphologies of the $\mathrm{ZnMoO}_{4}$ crystals. $^{85}$ 


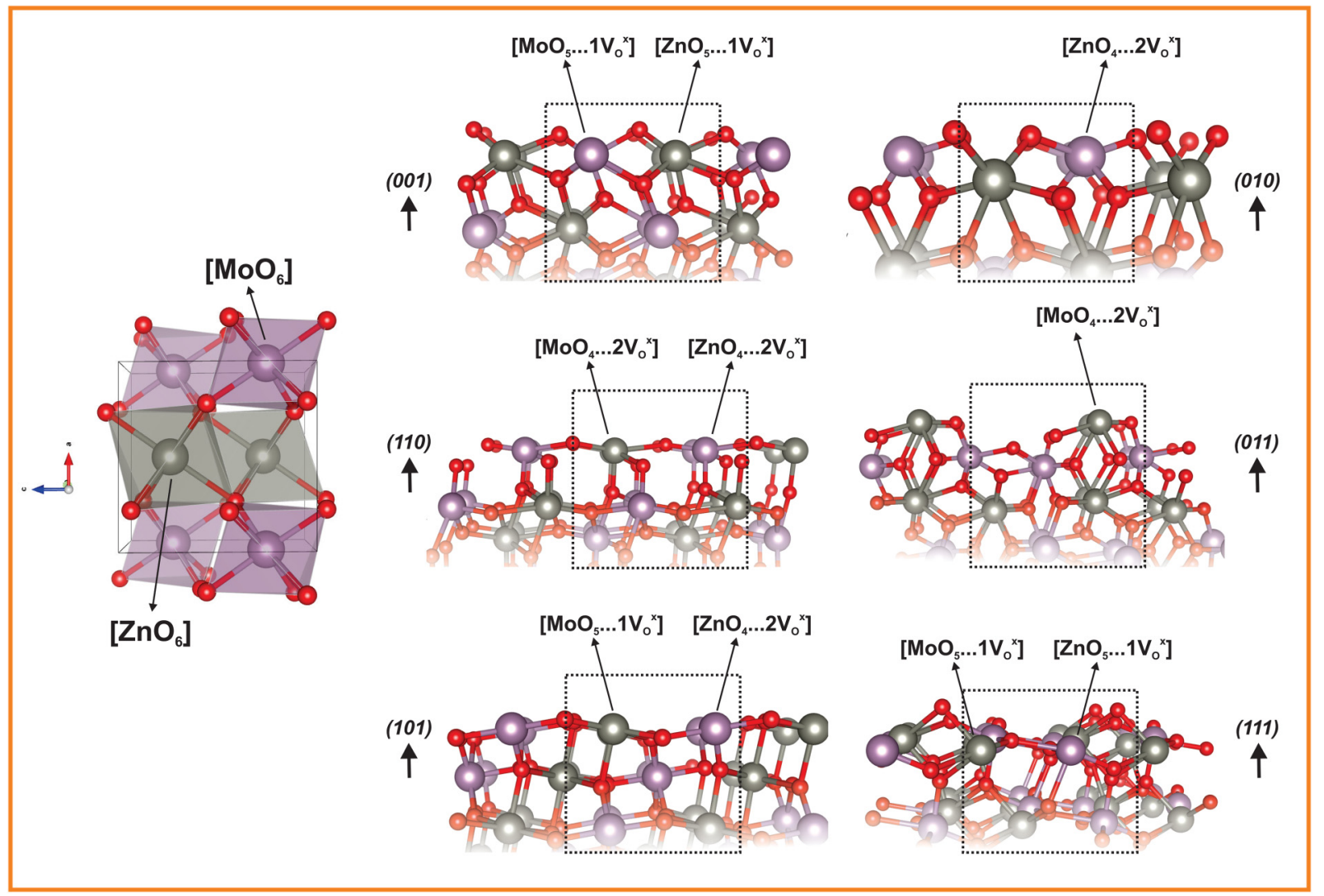

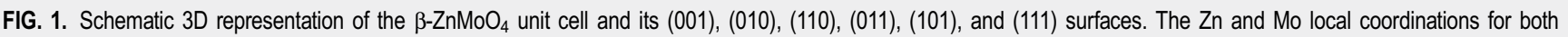
bulk and surface models are depicted.

\section{RESULTS AND DISCUSSIONS}

\section{A. Crystal structure, energy surface, and electronic properties}

First, let us analyze the structural properties of bulk and surfaces of $\beta-\mathrm{ZnMoO}_{4}$ based on the constituent clusters and existence of structural defects. The $\beta-\mathrm{ZnMoO}_{4}$ crystallizes in a wolframitetype monoclinic structure, space group $P 2 / c$ and point group symmetry $C_{2 h}^{4}$. In the monoclinic structure, the $\mathrm{Zn}$ and Mo cations are sixfold coordinated by oxygen anions to form the distorted octahedral $\left[\mathrm{ZnO}_{6}\right] /\left[\mathrm{MoO}_{6}\right]$ clusters, as presented in Fig. 1 . The calculated lattice parameters and $\mathrm{M}-\mathrm{O}(\mathrm{M}=\mathrm{Zn}, \mathrm{Mo})$ distances are presented in Table I and compared with previous experimental and theoretical results.

An analysis of the results reported in Table I shows good agreement with both experimental and theoretical studies available in the literature. In addition, the obtained results confirm that both octahedral $\left[\mathrm{ZnO}_{6}\right]$ and $\left[\mathrm{MoO}_{6}\right]$ clusters are distorted, showing three different values of $\mathrm{M}-\mathrm{O}$ bond lengths, with the Mo-O always being shorter than $\mathrm{Zn}-\mathrm{O}$.

From now, we briefly analyze the geometrical distribution of the (001), (010), (110), (011), (101), and (111) surfaces of
$\beta-\mathrm{ZnMoO}_{4}$ (Fig. 1). The cutting process connected to the surface structures can generate different kinds of undercoordinated centers from the existence of dangling bonds; an inherent process associated with the symmetry-adapted cutting strategy that can be associated with the presence of neutral oxygen vacancies $\left(V_{O}^{x}\right)$ along the exposed surfaces. In this case, the exposed local geometries were notably different compared to the bulk (Fig. 1).

The atomic arrangement of the (001) and (111) surfaces was described by a local coordination of fivefold $\mathrm{Zn} / \mathrm{Mo}$ cations, i.e., undercoordinated $\left[\mathrm{MoO}_{5} \ldots 1 V_{O}^{x}\right]$ and $\left[\mathrm{ZnO}_{5} \ldots 1 V_{O}^{x}\right]$ clusters, respectively. On the other hand, the obtained results indicate the generation of fourfold $\mathrm{Zn}$ or Mo centers, resulting in undercoordinated $\left[\mathrm{ZnO}_{4} \ldots 2 V_{O}^{x}\right]$ and $\left[\mathrm{MoO}_{4} \ldots 2 V_{O}^{x}\right]$ clusters for $(010)$ and (011) surfaces, respectively. In addition, the cutting process for the (110) surface indicates the existence of both undercoordinated $\left[\mathrm{ZnO}_{4} \ldots 2 V_{O}^{x}\right]$ and $\left[\mathrm{MoO}_{4} \ldots 2 V_{O}^{x}\right]$ clusters, while the (101) surface displays the existence of undercoordinated $\left[\mathrm{MoO}_{5} \ldots 1 V_{O}^{x}\right]$ and $\left[\mathrm{ZnO}_{4} \ldots 2 V_{O}^{x}\right]$ clusters.

It is well known that the geometrical arrangement of atoms at different exposed surfaces is related to the surface energetics due to the presence of different dangling bonds. Herein, we calculated the 
TABLE I. Lattice parameters and $\mathrm{M}-\mathrm{O}(\mathrm{M}=\mathrm{Zn}, \mathrm{Mo})$ bond distances for $\beta-\mathrm{ZnMOO}_{4}$. The available experimental and theoretical results were inserted for comparative purposes.

\begin{tabular}{|c|c|c|c|c|c|c|c|}
\hline & \multicolumn{5}{|c|}{ Lattice parameters } & \multicolumn{2}{|c|}{ Distances $(\AA)$} \\
\hline & a $(\AA)$ & b $(\AA)$ & $c(\AA)$ & $\beta$ (degree) & $\mathrm{V}\left(\AA^{3}\right)$ & $\mathrm{Zn}-\mathrm{O}$ & $\mathrm{Mo}-\mathrm{O}$ \\
\hline \multirow[t]{3}{*}{ This work } & 4.737 & 5.815 & 4.914 & 90.409 & 135.33 & $2.015(2 x)$ & $1.787(2 \mathrm{x})$ \\
\hline & & & & & & $2.091(2 \mathrm{x})$ & $1.902(2 x)$ \\
\hline & & & & & & $2.324(2 x)$ & $2.218(2 \mathrm{x})$ \\
\hline \multirow[t]{3}{*}{ Experimental $^{70}$} & 4.699 & 5.749 & 4.904 & 90.331 & 132.47 & $1.990(\mathrm{x})$ & $1.449(2 \mathrm{x})$ \\
\hline & & & & & & $2.308(2 x)$ & $1.849(2 \mathrm{x})$ \\
\hline & & & & & & $2.494(2 \mathrm{x})$ & $2.437(2 \mathrm{x})$ \\
\hline \multirow[t]{3}{*}{ Experimental $^{86}$} & 4.698 & 5.738 & 4.896 & 90.311 & 131.98 & $2.002(2 x)$ & $1.769(2 \mathrm{x})$ \\
\hline & & & & & & $2.093(2 x)$ & $1.894(2 \mathrm{x})$ \\
\hline & & & & & & $2.274(2 \mathrm{x})$ & $2.171(2 \mathrm{x})$ \\
\hline \multirow[t]{3}{*}{ Theoretical $^{70}$} & 4.739 & 5.810 & 5.089 & 90.647 & 140.12 & $2.033(2 x)$ & $1.795(2 \mathrm{x})$ \\
\hline & & & & & & $2.109(2 \mathrm{x})$ & $1.934(2 \mathrm{x})$ \\
\hline & & & & & & $2.149(2 \mathrm{x})$ & $2.143(2 \mathrm{x})$ \\
\hline
\end{tabular}

broken bonding density $\left(D_{\mathrm{b}}\right)$ index proposed by Gao et al. ${ }^{87}$ as the relation between the number of bonds broken per surface area as calculated from Eq. (2), where $N_{\mathrm{b}}$ is the number of broken bonds per unit cell area on a particular surface, and $A$ is the surface unit cell area,

$$
D_{b}=\frac{N_{b}}{A} .
$$

The calculated values of $\mathrm{E}_{\text {surf }}$ for the (001), (010), (110), (011), (101), and (111) surfaces of $\beta-\mathrm{ZnMoO}_{4}$ and its $D_{b}$ are summarized in Table II.

The calculated $\mathrm{E}_{\text {surf }}$ values reveal that the stability order is as follows: $(111)<(010)<(110)<(011)<(001)<(101)$. In addition, the $D_{b}$ values are intrinsically connected to the $\mathrm{E}_{\text {surf }}$ resulting in overall stability in comparison to the surfaces with reduced density of defects.

The electronic properties of bulk and surfaces of $\beta-\mathrm{ZnMoO}_{4}$ are analyzed by calculating the density of states (DOS) and band structure pictures, as presented in Fig. 2.

The analysis of the main components of the atomic orbitals (AOs) for selected bands shows that the bulk $\beta-\mathrm{ZnMoO}_{4}$ [Fig. 2(a)] valence band $(\mathrm{VB})$ mostly consists of the $2 \mathrm{p}$ orbitals of the $\mathrm{O}$ anions hybridized with the $3 \mathrm{~d}$ and $4 \mathrm{~d}$ valence orbitals of $\mathrm{Zn}$ and Mo cations, respectively. On the other hand, the conduction band

TABLE II. Values of $E_{\text {surf, }}$ area, broken bonding density $\left(D_{b}\right)$, and bandgap $\left(E_{\text {gap }}\right)$ calculated for the (001), (010), (110), (011), (101), and (111) surfaces of $\beta-\mathrm{ZnMoO}_{4}$.

\begin{tabular}{ccccc}
\hline \hline & $\mathrm{E}_{\text {surf }}\left(\mathrm{J} \mathrm{m}^{-2}\right)$ & Area $\left(\mathrm{nm}^{2}\right)$ & $D_{b}\left(\mathrm{~nm}^{-2}\right)$ & $\mathrm{E}_{\text {gap }}(\mathrm{eV})$ \\
\hline$(001)$ & 0.793 & 0.275 & 29.04 & 4.35 \\
$(010)$ & 0.674 & 0.233 & 17.19 & 3.73 \\
$(110)$ & 0.687 & 0.369 & 19.00 & 3.92 \\
$(011)$ & 0.761 & 0.361 & 19.41 & 4.37 \\
$(101)$ & 0.925 & 0.323 & 21.65 & 4.45 \\
$(111)$ & 0.551 & 0.461 & 15.18 & 4.60 \\
\hline \hline
\end{tabular}

(CB) shows the dominant composition of Mo valence states hybridized with oxygen orbitals. This profile indicates that the vertical excitation associated with the electronic transfer of electrons from valence band maximum (VBM) to conduction band minimum $(\mathrm{CBM})$ is associated with the electron transfer from $\mathrm{O}(2 \mathrm{p})$ states to empty orbital of Mo through the Mo-O bond path. Looking at the band structure, the vertical excitation was calculated as direct bandgap energy of $3.58 \mathrm{eV}$ between $\mathrm{X}-\mathrm{X}$ points, which is in agreement with previous experimental $(3.17 \mathrm{eV})$ and theoretical $(3.22 \mathrm{eV})$ results.

The electronic profiles of the (001), (010), (110), (011), (101), and (111) surfaces are shown in Figs. 2(b)-2(g). In this case, the calculated bandgap for each surface is presented in Table II. It was observed that the calculated bandgap for $\beta-\mathrm{ZnMoO}_{4}$ surfaces is higher than the bulk value in all cases, which can be associated with the presence of structural defects along the surfaces that affect both the CBM and VBM resulting in increased excitation energies.

\section{B. Crystal morphology}

The precise control of crystal morphology is an effective tool to tailor material properties. In the case of $\beta-\mathrm{ZnMoO}_{4}$, a series of experimental works have been developed in order to elucidate the shape-dependent properties of the monoclinic wolframite material, especially in the photoluminescence and photocatalysis fields. ${ }^{64,67,69,71,88}$ However, the reasons behind the shape-dependent properties remain unclear, with the combination of theory and simulation being an alternative tool in this research area that can guide the efficient synthesis of outstanding materials. The Wulff construction was employed in this study in order to rationalize the crystal morphologies, which is related to the relative stability of the exposed surfaces. The complete set of morphologies for the $\beta-\mathrm{ZnMoO}_{4}$ structure has been depicted in Fig. 3. The morphology evolution can be obtained by changing the ratio between the values of $E_{\text {surf }}$ for each surface, where the rate of each individual surface change is dependent on different $\mathrm{E}_{\text {surf }}$ values.

The equilibrium morphology of $\beta-\mathrm{ZnMoO}_{4}$ displays a cornertruncated hexagonal shape that predominantly exposed the (110), 


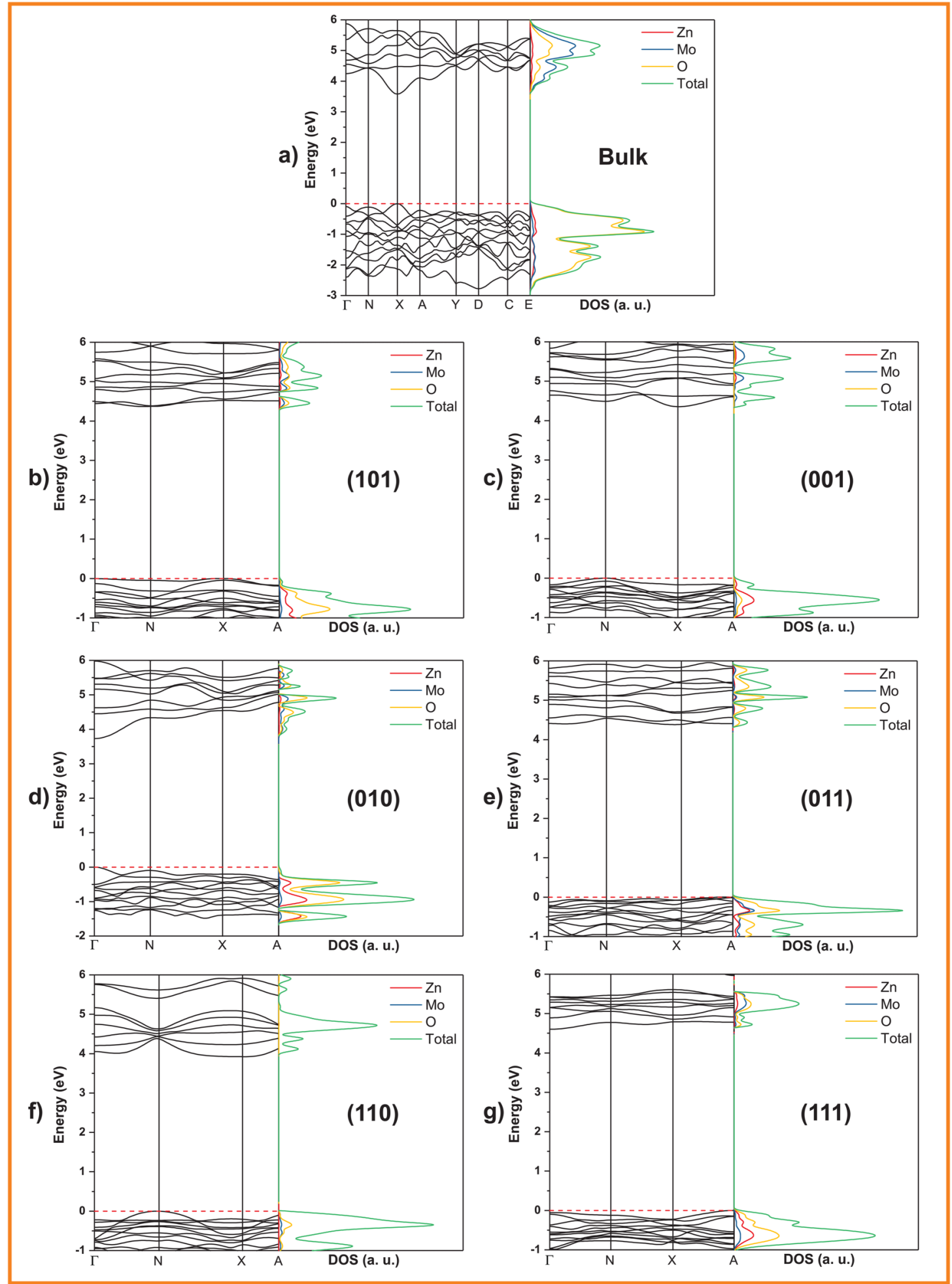

FIG. 2. Calculated band structures and DOS for (a) bulk $\beta-\mathrm{ZnMoO}_{4}$ and its (b) (101), (c) (001), (d) (010), (e) (011), (f) (110), and (g) (111) surfaces. 


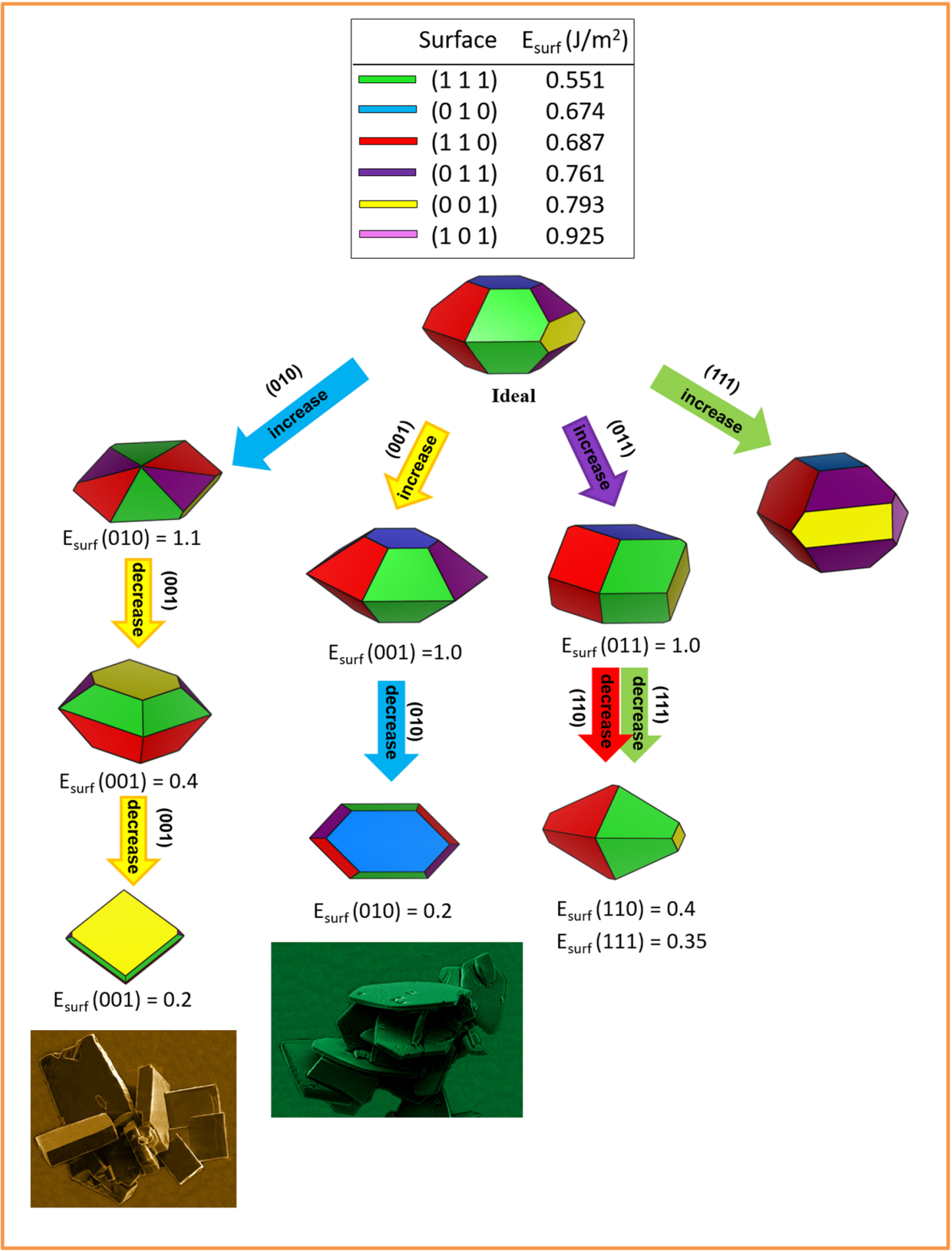

FIG. 3. Map of available morphologies of $\beta-Z n M_{0}{ }_{4}$ crystals. The experimental FE-SEM images from Ref. 69 (inset) are included for comparison. Reprinted from L. S. Cavalcante, J. C. Sczancoski, M. Siu Li, E. Longo, and J. A.Varela, Colloids Surf. A 396, 346-351. Copyright (2012) with permission from Elsevier. The experimental FE-SEM images (inset) are included for comparison. 
TABLE III. Values of $E_{\text {surf }}\left(\mathrm{J} \mathrm{m}^{-2}\right)$, contribution of the surface area by the total area $\left(C_{i}, \%\right)$, and the polyhedron energy $\left(E_{\text {pol }}, \mathrm{J} \mathrm{m}^{-2}\right)$ calculated for selected morphologies of $\beta-\mathrm{ZnOO}_{4}$

\begin{tabular}{|c|c|c|c|c|c|c|c|}
\hline \multicolumn{8}{|c|}{$\mathrm{E}_{\text {surf }}\left(C_{i}\right)$} \\
\hline Morphologies & $(001)$ & $(010)$ & (110) & $(011)$ & $(101)$ & (111) & $\mathrm{E}_{\text {pol }}$ \\
\hline Ideal & $0.793(10.0)$ & $0.674(10.2)$ & $0.687(30.0)$ & $0.761(12.8)$ & $0.925(0.0)$ & $0.551(37.1)$ & 0.655 \\
\hline $\mathrm{A}$ & $0.793(9.3)$ & $1.100(0.0)$ & $0.687(34.1)$ & $0.761(14.6)$ & $0.925(0.0)$ & $0.551(42.1)$ & 0.650 \\
\hline B & $0.400(33.9)$ & $1.000(0.0)$ & $0.687(28.5)$ & $0.761(2.7)$ & $0.925(0.0)$ & $0.551(34.9)$ & 0.544 \\
\hline $\mathrm{C}$ & $0.200(56.3)$ & $1.100(0.0)$ & 0.687 (19.8) & $0.761(0.1)$ & $0.925(0.0)$ & $0.551(23.8)$ & 0.381 \\
\hline $\mathrm{D}$ & $1.000(0.0)$ & $0.674(9.7)$ & $0.687(30.0)$ & $0.761(23.0)$ & $0.925(0.0)$ & $0.551(37.2)$ & 0.652 \\
\hline $\mathrm{E}$ & $1.000(0.0)$ & $0.200(54.7)$ & $0.687(14.8)$ & $0.761(12.1)$ & $0.925(0.0)$ & $0.551(18.4)$ & 0.405 \\
\hline
\end{tabular}

(111), (010), (011), and (001) surfaces. Using the Wulff construction renders that the (110), (111), (010), (011), and (001) facets account for $30.0 \%, 37.1 \%, 10.2 \%, 12.8 \%$, and $10.0 \%$, respectively. The two low-energy (110) and (111) surfaces dominate in the Wulff shape and make up almost $70 \%$ of the total crystal shape area. In addition, it was observed that different shapes were obtained by tuning $\mathrm{E}_{\text {surf }}$ for $\beta-\mathrm{ZnMoO}_{4}$, such as truncated and nontruncated rectangular, hexagonal, octahedral, and rhombic shapes matching the experimental morphologies obtained by examining the FE-SEM images. ${ }^{64,67,69,71,88}$ These experimentally observed morphologies should be close to the equilibrium shapes under the experimental conditions.

From a thermodynamic point of view, the morphology is controlled by relative stability of different surfaces, and the surface with the lowest $E_{\text {surf }}$ value is the main component of the corresponding morphology. Adjusting the ratio of the $\mathrm{E}_{\text {surf }}$ values of the three surfaces enables obtaining different morphologies, and the corresponding reaction paths can be isolated and studied independently. This procedure can be considered an effective tool to investigate the morphology transformation and crystal growth mechanisms from a thermodynamic and kinetic point of view ${ }^{55,89}$ and can provide useful insights for fabricating $\mathrm{ZnMoO}_{4}$ materials with suitable morphologies for a wide variety of specific devices and purposes.

In this study, we were able to calculate the energy profiles of the paths connecting different morphologies from the values of the polyhedron energy $\left(\mathrm{E}_{\mathrm{pol}}\right)$ by a function of the form as follows: $:^{89,90}$

$$
\mathrm{E}_{\mathrm{pol}}=\sum C_{i} x \mathrm{E}_{\mathrm{surf}}^{i}
$$

where $C_{i}$ is the percentage contribution of the surface area to the total surface area of the polyhedron, $C_{i}=A^{i} / A^{\text {polyhedron }}$ and $\mathrm{E}_{\text {surf }}^{i}$ is the surface energy of the corresponding surface. The energy profiles were calculated by decreasing and/or increasing the $\mathrm{E}_{\text {surf }}$ values of a given surface of the polyhedron.

Two pathways connecting the ideal morphology with those displaying excellent agreement with the experimental morphologies were calculated. Polyhedron energy $\left(\mathrm{E}_{\mathrm{pol}}\right)$ calculated from Eq. (3) for the selected morphology of $\beta-\mathrm{ZnMoO}_{4}$ is summarized in Table III.

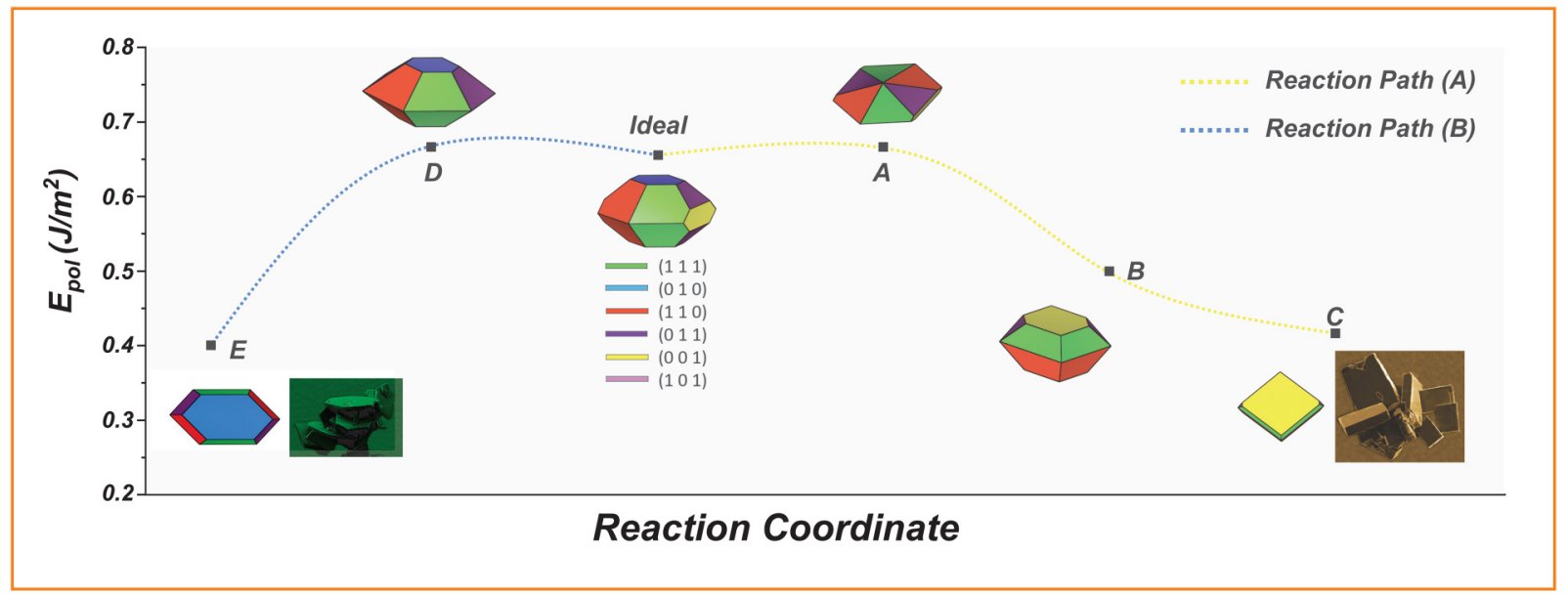

FIG. 4. Schematic representation of the energy profile for different $\beta-\mathrm{ZnMoO}_{4}$ morphologies. Intermediate morphologies were obtained by a decrease/increase in $\mathrm{E}_{\text {surf }}$ values involved in the process. The experimental FE-SEM images from Ref. 69 (inset) are included for comparison. Reprinted from L. S. Cavalcante, J. C. Sczancoski, M. Siu Li, E. Longo, and J. A. Varela, Colloids Surf. A 396, 346-351. Copyright (2012) with permission from Elsevier. The experimental FE-SEM images (inset) are included for comparison. 
The first one, reaction path (A), considers the increase of the $E_{\text {surf }}$ value for (010) and a posterior decrease of $E_{\text {surf }}$ for (001), which induces forming a rectangular $(\mathrm{C})$ shape that predominantly exposes the (001) surface plane, and is in agreement with experimental findings. On the other hand, the reaction path (B) moves from the ideal path with an increase in the $E_{\text {surf }}$ value for (001), and a posterior decrease of $\mathrm{E}_{\text {surf }}$ for $(010)$ generates a hexagonal plate (E) that predominantly exposes the (010) surface plane. It is important to point out that both theoretical morphologies labeled $\mathrm{C}$ and $\mathrm{E}$ herein correspond to a minimum in the reaction coordinate diagram as depicted in Fig. 4, indicating that both reaction paths are thermodynamically favorable, as proven by the experimental reproduction of such morphologies.

From the experimental point of view, the authors state that distinct surfactants changed the shape and average size of $\beta-\mathrm{ZnMoO}_{4}$ microcrystals. In addition, they point out that the chemical nature of the surfactants (cationic, anionic, and nonionic) can interact differently with the $\mathrm{Zn}^{2+}$ and $\left[\mathrm{MoO}_{4}\right]^{2-}$ ions in solution, influencing the formation and growth process of the microcrystals. $^{59}$ In looking at the geometrical characteristics of both (010) and (001) surfaces, the distinct exposed clusters can interact with the surfactants to generate different crystal morphologies. For example, the (010) surface shows a smaller broken bond density (Table I) in comparison to the (001) surface, thus suggesting a more negative charge character for the (010) surface due to the presence of a high number of saturated bonds along the exposed plane. On the other hand, it is expected that the (001) surface shows a more positive charge concentration due to the increased unsaturation degree observed for this plane. Those facts can be directly compared to the interaction between cationic and anionic surfactants that results in the obtained shapes.

Therefore, the obtained morphological map is a fundamental tool to understand the morphological transformation associated with $\beta-\mathrm{ZnMoO}_{4}$, with the additional morphologies proposed in this study constituting alternative possibilities that can guide experimental studies toward enhanced technological properties. The next step will be to use the present results to establish correlation between the morphology, properties, and applications, such as those which our group have developed for $\mathrm{Co}_{3} \mathrm{O}_{4},{ }^{33} \mathrm{MnTiO}_{3},{ }^{91} \mathrm{CaZrO}_{3}: \mathrm{Eu}^{3+}, \mathrm{ZnO}^{93}$ $\mathrm{Ag}_{3} \mathrm{PO}_{4},{ }^{94} \alpha-\mathrm{Ag}_{2} \mathrm{WO}_{4},{ }^{89,95} \mathrm{PbMoO}_{4},{ }^{60}$ and $\mathrm{ZnWO}_{4}{ }^{96,97}$

\section{CONCLUSIONS}

Motivated by the interest in the $\beta-\mathrm{ZnMoO}_{4}$ material, its exposed surface and morphology are studied in detail by the first-principle calculations at the density functional theory level. The values of the energy surfaces and their atomic and electronic arrangement of different low-index surfaces (001), (010), (110), (011), (101), and (111) of $\beta-\mathrm{ZnMoO}_{4}$ are calculated. Analysis of the surface structures showed that the surface energies and electronic properties were associated with the presence of undercoordinated $\left[\mathrm{MoO}_{\mathrm{n}} \ldots y V_{O}^{x}\right]$ and $\left[\mathrm{ZnO}_{\mathrm{n}} \ldots y V_{O}^{x}\right](\mathrm{n}=4$ and $5 ; \mathrm{y}=1$ and 2$)$ clusters. A complete map of the available morphologies was obtained based on these results and by using the Wulff construction, and it was revealed that the theoretical morphologies match with previously reported experimental morphologies when the surface energy values of the (010) and (001) surfaces were $0.2 \mathrm{~J} / \mathrm{m}^{2}$. The present findings will help us to further understand and control the available morphologies of $\beta-\mathrm{ZnMoO}_{4}$ crystals and suggest potential strategies to indicate the morphology transformation.

\section{ACKNOWLEDGMENTS}

This work was supported by the Federal University of São Carlos, Federal University of Rio Grande do Norte (PPGCEMUFRN), State University of Ponta Grossa, University of Jaume I, CAPES, PDSE-CAPES, CNPq, and Fundação Araucária (009/2017). R. A. P. Ribeiro acknowledges financial support from CNPq 156176/ 2018-1. M. C. Oliveira acknowledges the financial support from PNPD/CAPES (No. 2019/88887.319041). J. Andrés acknowledges Universitat Jaume I for the project UJIB2016-25, Generalitat Valenciana for projects PrometeoII/2014/022, ACOMP/2014/270, and ACOMP/2015/1202, as well as Ministerio de Economia y Competitividad (Spain) ProjectCTQ2015-65207-P for financial support. E. Longo acknowledges financial support from FAPESP 2013/07296-2.

\section{REFERENCES}

${ }^{1}$ S. Bai, L. Wang, Z. Li, and Y. Xiong, Adv. Sci. 4, 1600216 (2017).

${ }^{2}$ S. Sun, X. Zhang, J. Cui, Q. Yang, and S. Liang, Nanoscale 11, 15739 (2019).

${ }^{3}$ Y. Luo, L. Tang, U. Khan, Q. Yu, H.-M. Cheng, X. Zou, and B. Liu, Nat. Commun. 10, 269 (2019).

${ }^{4}$ W. Huang, Acc. Chem. Res. 49, 520 (2016).

${ }^{5}$ S. Polarz, Adv. Funct. Mater. 21, 3214 (2011).

${ }^{6}$ H. G. Yang, C. H. Sun, S. Z. Qiao, J. Zou, G. Liu, S. C. Smith, H. M. Cheng, and G. Q. Lu, Nature 453, 638 (2008).

${ }^{7}$ Y.-K. Peng and S. C. E. Tsang, Nano Today 18, 15 (2018).

${ }^{8}$ M. H. Huang and M. Madasu, Nano Today 28, 100768 (2019).

${ }^{9}$ C. McDowell, M. Abdelsamie, M. F. Toney, and G. C. Bazan, Adv. Mater. 30, 1707114 (2018).

${ }^{10}$ X. Huang, G. Alva, Y. Jia, and G. Fang, Renew. Sust. Energ. Rev. 72, 128 (2017).

${ }^{11}$ H. Lee, C. Park, D. H. Sin, J. H. Park, and K. Cho, Adv. Mater. 30, 1800453 (2018).

${ }^{12}$ A. Rani, R. Reddy, U. Sharma, P. Mukherjee, P. Mishra, A. Kuila, L. C. Sim, and P. Saravanan, J. Nanostruct. Chem. 8, 255 (2018).

${ }^{13}$ P. Dandekar, Z. B. Kuvadia, and M. F. Doherty, Annu. Rev. Mater. Res. 43, 359 (2013).

${ }^{14}$ J. Jeevanandam, A. Barhoum, Y. S. Chan, A. Dufresne, and M. K. Danquah, Beilstein J. Nanotechnol. 9, 1050 (2018).

${ }^{15}$ Y. B. Vogel, J. Zhang, N. Darwish, and S. Ciampi, ACS Nano 12, 8071 (2018). ${ }^{16}$ M. H. Huang, Small 15, 1804726 (2019).

${ }^{17}$ G. D. Barmparis, Z. Lodziana, N. Lopez, and I. N. Remediakis, Beilstein J. Nanotechnol. 6, 361 (2015).

${ }^{18}$ E. Bittarello, M. Bruno, and D. Aquilano, Cryst. Growth Des. 18, 4084 (2018).

${ }^{19}$ P. P. Dholabhai, R. Perriot, and B. P. Uberuaga, J. Phys. Chem. C 120, 10485 (2016).

${ }^{20}$ Z. Gao, C. Li, W. Sun, and Y. Hu, Colloids Surf. A 520, 53 (2017).

${ }^{21}$ B. Zhu, Z. Xu, C. Wang, and Y. Gao, Nano Lett. 16, 2628 (2016).

${ }^{22}$ A. S. Barnard, Nanoscale 6, 9983 (2014).

${ }^{23}$ F. Lai, Y. Chen, and H. Guo, J. Cryst. Growth 508, 1 (2019).

${ }^{24}$ F. Lai, Y. Chen, and H. Guo, Phys. Chem. Chem. Phys. 21, 16486 (2019).

${ }^{25}$ J. J. Gilman, J. Appl. Phys. 31, 2208 (1960).

${ }^{26}$ W. R. Tyson and W. A. Miller, Surf. Sci. 62, 267 (1977).

${ }^{27}$ D. J. Eaglesham, A. E. White, L. C. Feldman, N. Moriya, and D. C. Jacobson, Phys. Rev. Lett. 70, 1643 (1993). 
${ }^{28}$ C. Bombis, A. Emundts, M. Nowicki, and H. P. Bonzel, Surf. Sci. 511, 83 (2002).

${ }^{29}$ J. J. Métois and P. Müller, Surf. Sci. 548, 13 (2004).

${ }^{30}$ M. T. Fabbro, C. C. Foggi, L. P. S. Santos, L. Gracia, A. Perrin, C. Perrin, C. E. Vergani, A. L. Machado, J. Andrés, E. Cordoncillo, and E. Longo, Dalton Trans. 45, 10736 (2016).

${ }^{31}$ M. M. Ferrer, A. F. Gouveia, L. Gracia, E. Longo, and J. Andrés, Modell. Simul. Mater. Sci. Eng. 24, 025007 (2016).

${ }^{32}$ J. Andrés, L. Gracia, A. F. Gouveia, M. M. Ferrer, and E. Longo, Nanotechnology 26, 405703 (2015).

${ }^{33}$ R. A. P. Ribeiro, S. R. de Lazaro, L. Gracia, E. Longo, and J. Andrés, J. Magn. Magn. Mater. 453, 262 (2018).

${ }^{34}$ A. Iglesias-Juez, F. Viñes, O. Lamiel-García, M. Fernández-García, and F. Illas, J. Mater. Chem. A 3, 8782 (2015).

${ }^{35}$ J. He, Á. Morales-García, O. Bludský, and P. Nachtigall, CrystEngComm 18, 3808 (2016).

${ }^{36}$ E. Osei-Agyemang, J.-F. Paul, R. Lucas, S. Foucaud, and S. Cristol, J. Phys. Chem. C 120, 8759 (2016).

${ }^{37}$ T. Stirner, D. Scholz, and J. Sun, Surf. Sci. 671, 11 (2018).

${ }^{38}$ Q. Cai, J.-G. Wang, Y. Wang, and D. Mei, J. Phys. Chem. C 120, 19087 (2016).

${ }^{39}$ M. A. Asoro, D. Kovar, Y. Shao-Horn, L. F. Allard, and P. J. Ferreira, Nanotechnology 21, 025701 (2009).

${ }^{40}$ C. S. Bonifacio, S. Carenco, C. H. Wu, S. D. House, H. Bluhm, and J. C. Yang, Chem. Mater. 27, 6960 (2015).

${ }^{41}$ H. Chen, Y. Yu, H. L. Xin, K. A. Newton, M. E. Holtz, D. Wang, D. A. Muller, H. D. Abruña, and F. J. DiSalvo, Chem. Mater. 25, 1436 (2013).

${ }^{42} \mathrm{~N}$. Lu, J. Wang, S. Xie, Y. Xia, and M. J. Kim, Chem. Commun. 49, 11806 (2013).

${ }^{43} \mathrm{~J}$. Wu, W. Gao, J. Wen, D. J. Miller, P. Lu, J.-M. Zuo, and H. Yang, Nano Lett. 15, 2711 (2015).

${ }^{44}$ A. S. Barnard, X. M. Lin, and L. A. Curtiss, J. Phys. Chem. B 109, 24465 (2005).

${ }^{45}$ N. P. Young, M. A. van Huis, H. W. Zandbergen, H. Xu, and A. I. Kirkland, Ultramicroscopy 110, 506 (2010).

${ }^{46}$ Q. Wang, H.-T. Yu, Y. Xie, M.-X. Li, T.-F. Yi, C.-F. Guo, Q.-S. Song, M. Lou, and S.-S. Fan, J. Power Sources 319, 185 (2016).

${ }^{47}$ M. Jin, H. Zhang, Z. Xie, and Y. Xia, Angew. Chem. Int. Ed. 50, 7850 (2011).

${ }^{48}$ J. Zhang, L. Zhang, S. Xie, Q. Kuang, X. Han, Z. Xie, and L. Zheng, Chem. Eur. J. 17, 9915 (2011).

${ }^{49}$ J. Zhang, M. R. Langille, M. L. Personick, K. Zhang, S. Li, and C. A. Mirkin, J. Am. Chem. Soc. 132, 14012 (2010).

${ }^{50} \mathrm{X}$. Wang, H.-F. Wu, Q. Kuang, R.-B. Huang, Z.-X. Xie, and L.-S. Zheng, Langmuir 26, 2774 (2010).

${ }^{51}$ N. Zhao, W. Ma, Z. Cui, W. Song, C. Xu, and M. Gao, ACS Nano 3, 1775 (2009).

${ }^{52}$ X. Xie, Y. Li, Z.-Q. Liu, M. Haruta, and W. Shen, Nature 458, 746 (2009).

${ }^{53}$ R. L. Tranquilin, L. X. Lovisa, C. R. R. Almeida, C. A. Paskocimas, M. S. Li, M. C. Oliveira, L. Gracia, J. Andres, E. Longo, F. V. Motta, and M. R. D. Bomio, J. Phys. Chem. C 123, 18536 (2019).

${ }^{54}$ F. K. F. Oliveira, M. C. Oliveira, L. Gracia, R. L. Tranquilin, C. A. Paskocimas, F. V. Motta, E. Longo, J. Andrés, and M. R. D. Bomio, J. Phys. Chem. Solids 114, 141 (2018).

${ }^{55}$ L. X. Lovisa, M. C. Oliveira, J. Andrés, L. Gracia, M. S. Li, E. Longo, R. L. Tranquilin, C. A. Paskocimas, M. R. D. Bomio, and F. V. Motta, J. Alloys Compd. 750, 55 (2018).

${ }^{56}$ J. Andrés, M. M. Ferrer, L. Gracia, A. Beltran, V. M. Longo, G. H. Cruvinel, R. L. Tranquilin, and E. Longo, Part. Part. Syst. Charact. 32, 646 (2015).

${ }^{57}$ A. Beltrán, L. Gracia, E. Longo, and J. Andrés, J. Phys. Chem. C 118, 3724 (2014).

${ }^{58}$ V. D. Araújo, R. L. Tranquilin, F. V. Motta, C. A. Paskocimas, M. I. B. Bernardi, L. S. Cavalcante, J. Andres, E. Longo, and M. R. D. Bomio, Mater. Sci. Semicond. Process. 26, 425 (2014).
${ }^{59}$ M. R. D. Bomio, L. S. Cavalcante, M. A. P. Almeida, R. L. Tranquilin, N. C. Batista, P. S. Pizani, M. Siu Li, J. Andres, and E. Longo, Polyhedron 50, $532(2013)$.

${ }^{60}$ M. R. D. Bomio, R. L. Tranquilin, F. V. Motta, C. A. Paskocimas, R. M. Nascimento, L. Gracia, J. Andres, and E. Longo, J. Phys. Chem. C 117, 21382 (2013).

${ }^{61}$ V. M. Longo, L. S. Cavalcante, E. C. Paris, J. C. Sczancoski, P. S. Pizani, M. S. Li, J. Andrés, E. Longo, and J. A. Varela, J. Phys. Chem. C 115, 5207 (2011).

${ }^{62}$ J. C. Sczancoski, L. S. Cavalcante, N. L. Marana, R. O. da Silva, R. L. Tranquilin, M. R. Joya, P. S. Pizani, J. A. Varela, J. R. Sambrano, M. Siu Li, E. Longo, and J. Andrés, Curr. Appl. Phys. 10, 614 (2010).

${ }^{63}$ J. C. Sczancoski, M. D. R. Bomio, L. S. Cavalcante, M. R. Joya, P. S. Pizani, J. A. Varela, E. Longo, M. S. Li, and J. A. Andrés, J. Phys. Chem. C 113, 5812 (2009).

${ }^{64}$ Y.-R. Jiang, W. W. Lee, K.-T. Chen, M.-C. Wang, K.-H. Chang, and C.-C. Chen, J. Taiwan Inst. Chem. Eng. 45, 207 (2014).

${ }^{65}$ D. A. Spassky, A. N. Vasil'ev, I. A. Kamenskikh, V. V. Mikhailin, A. E. Savon, Y. A. Hizhnyi, S. G. Nedilko, and P. A. Lykov, J. Phys. Condens. Matter 23, 365501 (2011).

${ }^{66}$ S. Bhattacharya, T. Kar, A. K. Bar, D. Roy, M. P. F. Graca, and M. A. Valente, Sci. Adv. Mater. 3, 284 (2011).

${ }^{67}$ Y. Keereeta, T. Thongtem, and S. Thongtem, Superlattices Microstruct. 69, 253 (2014).

${ }^{68}$ Y. Keereeta, T. Thongtem, and S. Thongtem, Mater. Lett. 68, 265 (2012).

${ }^{69}$ L. S. Cavalcante, J. C. Sczancoski, M. Siu Li, E. Longo, and J. A. Varela, Colloids Surf. A 396, 346 (2012).

${ }^{70}$ L. S. Cavalcante, E. Moraes, M. A. P. Almeida, C. J. Dalmaschio, N. C. Batista, J. A. Varela, E. Longo, M. Siu Li, J. Andrés, and A. Beltrán, Polyhedron 54, 13 (2013).

${ }^{\mathbf{7 1}}$ C.-C. Chen, H.-J. Fan, J. Shaya, Y.-K. Chang, V. B. Golovko, O. Toulemonde, C.-H. Huang, Y.-X. Song, and C.-S. Lu, Appl. Organomet. Chem. 33, e5113 (2019).

${ }^{72}$ R. Dovesi, R. Orlando, A. Erba, C. M. Zicovich-Wilson, B. Civalleri, S. Casassa, L. Maschio, M. Ferrabone, M. De La Pierre, P. D’Arco, Y. Noël, M. Causà, M. Rérat, and B. Kirtman, Int. J. Quantum Chem. 114, 1287 (2014).

${ }^{73}$ S. H. Vosko, L. Wilk, and M. Nusair, Can. J. Phys. 58, 1200 (1980).

${ }^{74}$ A. D. Becke, J. Chem. Phys. 98, 5648 (1993).

${ }^{75}$ R. A. P. Ribeiro, S. R. de Lazaro, and S. A. Pianaro, J. Magn. Magn. Mater. 391, 166 (2015).

${ }^{76}$ R. I. Eglitis and A. I. Popov, J. Saudi Chem. Soc. 22, 459 (2018).

77R. I. Eglitis, Solid State Ionics 230, 43 (2013).

${ }^{78}$ E. Heifets, E. A. Kotomin, A. A. Bagaturyants, and J. Maier, J. Phys. Chem. Lett. 6, 2847 (2015).

${ }^{79}$ E. Heifets, E. A. Kotomin, A. A. Bagaturyants, and J. Maier, Phys. Chem. Chem. Phys. 19, 3738 (2017).

${ }^{80}$ H. J. Monkhorst and J. D. Pack, Phys. Rev. B Condens. Matter Mater. Phys. 13, 5188 (1976).

${ }^{81}$ J. E. Jaffe and A. C. Hess, Phys. Rev. B Condens. Matter Mater. Phys. 48, 7903 (1993).

${ }^{82}$ M. Corno, C. Busco, B. Civalleri, and P. Ugliengo, Phys. Chem. Chem. Phys. 8, 2464 (2006)

${ }^{83}$ F. Corà, A. Patel, N. M. Harrison, C. Roetti, C. Richard, and A. Catlow, J. Mater. Chem. 7, 959 (1997).

${ }^{84}$ G. Wulff, Z. Kristallogr. - Cryst. Mater. 34, 449 (2015).

${ }^{85} \mathrm{~K}$. Momma and F. Izumi, J. Appl. Crystallogr. 44, 1272 (2011).

${ }^{86}$ O. Mtioui-Sghaier, R. Mendoza-Merono, L. Ktari, M. Dammak, and S. Garcia-Granda, Acta Crystallogr. Sect. E 71, i6 (2015).

${ }^{\mathbf{8 7}}$ Z.-Y. Gao, W. Sun, and Y.-H. Hu, Trans. Nonferrous Met. Soc. China 24, 2930 (2014).

${ }^{88}$ L. Lv, W. Tong, Y. Zhang, Y. Su, and X. Wang, J. Nanosci. Nanotechnol. 11, 9506 (2011). 
${ }^{89}$ N. G. Macedo, A. F. Gouveia, R. A. Roca, M. Assis, L. Gracia, J. Andrés, E. R. Leite, and E. Longo, J. Phys. Chem. C 122, 8667 (2018).

${ }^{90}$ R. A. P. Ribeiro, L. H. S. Lacerda, E. Longo, J. Andrés, and S. R. de Lazaro, J. Magn. Magn. Mater. 475, 544 (2019).

${ }^{91}$ R. A. P. Ribeiro, J. Andrés, E. Longo, and S. R. Lazaro, Appl. Surf. Sci. 452, 463 (2018).

${ }^{92}$ M. C. Oliveira, R. A. P. Ribeiro, L. Gracia, S. R. de Lazaro, M. de Assis, M. Oliva, I. L. V. Rosa, M. F. do C. Gurgel, E. Longo, and J. Andrés, CrystEngComm 20, 5519 (2018).

${ }^{93}$ G. Byzynski, C. Melo, D. P. Volanti, M. M. Ferrer, A. F. Gouveia, C. Ribeiro, J. Andrés, and E. Longo, Mater. Des. 120, 363 (2017).
${ }^{94}$ A. B. Trench, T. R. Machado, A. F. Gouveia, M. Assis, L. G. da Trindade, C. Santos, A. Perrin, C. Perrin, M. Oliva, J. Andrés, and E. Longo, Appl. Catal. B 238, 198 (2018).

${ }^{95}$ R. A. Roca, J. C. Sczancoski, I. C. Nogueira, M. T. Fabbro, H. C. Alves, L. Gracia, L. P. S. Santos, C. P. de Sousa, J. Andrés, G. E. Luz, E. Longo, and L. S. Cavalcante, Catal. Sci. Technol. 5, 4091 (2015).

${ }^{96}$ P. F. S. Pereira, A. F. Gouveia, M. Assis, R. C. de Oliveira, I. M. Pinatti, M. Penha, R. F. Gonçalves, L. Gracia, J. Andrés, and E. Longo, Phys. Chem. Chem. Phys. 20, 1923 (2018).

${ }^{97}$ A. F. Gouveia, M. Assis, L. S. Cavalcante, L. Gracia, E. Longo, and A. Juan, Front. Res. Today 1, 1005 (2018). 